\title{
A Novel Fault Location Scheme on Korean Electric Railway System Using the 9-Conductor Representation
}

\author{
Changmu Lee*, Hansang Lee**, Dong-Hee Yoon**, Hanmin Lee*, \\ Jiyoung Song**, Gilsoo Jang ${ }^{\dagger}$ and Byungmoon Han***
}

\begin{abstract}
This paper presents a novel fault location scheme on Korean AC electric railway systems. On AC railway system, because of long distance, $40[\mathrm{~km}]$ or above, between two railway substations, a fault location technique is very important. Since the fault current flows through the catenary system, it must be modeled exactly to analyze the fault current magnitude and fault location. In this paper, suggesting the novel scheme of fault location, a 9-conductor modeling technique including boost wires and impedance bonds is introduced based on the characteristics of Korean AC electric railway. After obtaining a 9-conductor modeling, the railway system is constructed for computer simulation by using PSCAD/EMTDC. By case studies, we can verify superiority of a new fault location scheme and propose a powerful model for fault analysis on electric railway systems.
\end{abstract}

Keywords: Fault analysis, Boost wire, Korea AC electric railway system, Fault current ratio

\section{Introduction}

An electric railway system has a number of advantages in terms of traffic capability, energy efficiency, operational cost and environmental friendliness in comparison with other transportation systems [1]. However, the faults threatening safety of passengers or normal operations of electric railway system are inevitable. Especially, since the electric railway systems are combined with static and dynamic electrical system, the probability of fault occurrence is much higher than general electric power systems [2]. Actually, railway vehicles supply electric power through pantographs that play roles as junction between static and dynamic electrical system. As the vehicles run, the catenary systems experience frictional wear and snapping finally. Because of these reasons, the fault analysis on electric railway system has been a main research theme.

Before performing fault analysis, first of all, it is important to model Korean AC electric railway system. The existing model which has been used on fault analysis is 5conductor reduced equivalent modeling [3] by using reduced equivalent method [4]. However, this 5-conductor reduced equivalent model does not consider boost wires and impedance bonds. The boost wires are connections between protection wires and rail to absorb the current flowing on rail [5] and the impedance bonds are connections of two protection wires, two rails, and buried earth wires to reduced total impedance of these 5 conductors by placing them parallel. The 5 -conductor reduced equivalent

$广 \quad$ Corresponding Author: Department of Electrical Engineering, Korea University(gjang@korea.ac.kr)

* Korea Railroad Research Institute(cmlee@krri.re.kr, hanmin@krri.re.kr)

** Department of Electrical Engineering, Korea University (hansang80@korea.ac.kr, dongace@korea.ac.kr, riddle23@korea.ac.kr)

*** Electrical Engineering, Myongji University(erichan@mju.ac.kr)

Received : November 30, 2009; Accepted : March 27, 2010 model is not suitable for a novel fault location scheme in this paper, because the model does not represent the boost wires and impedance bonds. To make the model appropriate for a novel scheme, the 9-conductor reduced equivalent model, which is composed of 2 feeders, 2 protection wires, 1 buried ground wire, 2 contact wire conductor group, and 2 rail conductor group, is suggested by using PSCAD/ EMTDC [6]. The contact wire conductor group is reducedexpression for contact wire and messenger wire, and the rail conductor group is reduced one for four rail conductors.

An existing fault location scheme is to calculate current ratio by estimating fault current on two autotransformers [5], [7]-[8]. However, in Korean electric railway system, railway substations are located in every 40 50 [km], and 3 auto-transformers are placed at sectioning post and parallel post between two substations. That is, the distance between two autotransformers is about $10[\mathrm{~km}]$. Although this scheme is very accurate and its locating error rate is $1 \sim 2 \%$, the actual locating error is to be 100 200 [m] because the distance between two fault current detectors is about 10 [km].

As the faulted catenary system may cause railway vehicles operation interrupted, they should be restored as soon as possible. Moreover, since unmanned automation technique on railway substation is one of the electrical technique trends, it takes much longer to restore the faulted system. By these reasons, the railway system operators need to bring down restoring time. The one of the most effective way to bring down the restoring time is to find the fault location accurately. However, since to reduce the error in the existing fault location scheme is physically impossible, the novel fault location scheme employs a number of current sensors on the boost wire which are placed in every $1.2[\mathrm{~km}]$. The location error can be reduced significantly by installing detectors closely. If the novel scheme has same location error rate with conservative scheme, the location error is to be 12 24 [m]. 


\section{Korean AC Electric Railway Systems}

The Korean AC electric railway systems are based on single-phase $55 / 27.5[\mathrm{kV}]$ AC feeding circuits supply electric trains with electric power via three-to-two-phase Scott transformers, feeders, contact wires, and rails. The autotransformer is designed with a turn ratio of 1:1. The parallel post(PP) is located at approximately every $10[\mathrm{~km}]$. Substations (SS) are located in every $40 \sim 50[\mathrm{~km}]$ and a sectioning post (SP) is located at the middle of two substations. The SP has circuit breakers which enable one feeding circuit to separate electrically from the other circuit. They may be closed in case the adjacent SS is out of service. General electric railway system in Korea is illustrated on Fig. 1.

To analyze the AC railway system accurately, it is important to construct a catenary system model, because the fault current flows on the catenary system by impedance ratio. With defining the equivalent model for catenary system, other parts should be constructed exactly. Models for KEPCO power system, Scott transformer, and autotransformer are followed.

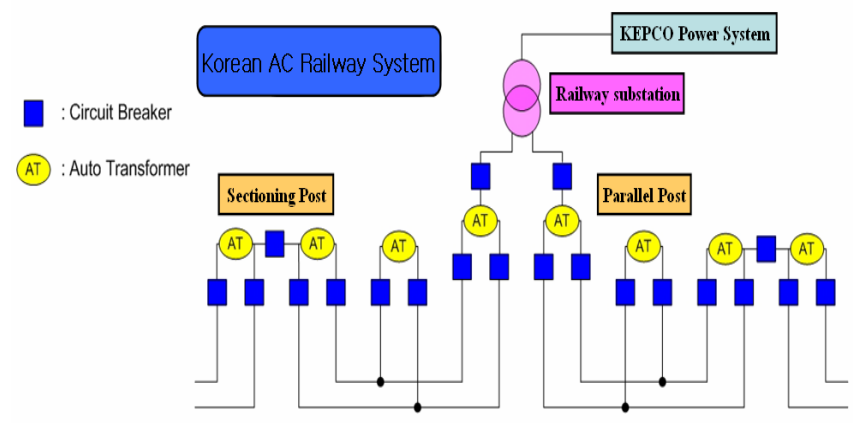

Fig. 1. Configuration of Korean AC railway system.

\subsection{KEPCO Power System}

The Korean AC railway systems are supplied with electric power from KEPCO power system by $154[\mathrm{kV}]$. In this paper, the electric source model is modeled as voltage source and source impedance. The voltage magnitude of the voltage source is $154[\mathrm{kV}]$ as line-to-line rms value. The source impedance parameters can be obtained from sequence data of the KEPCO power system. The impedance parameters can be seen as below.

Table 1. Source impedance parameters

\begin{tabular}{c|c|c}
\hline Sequence & Percent impedance & Base value \\
\cline { 1 - 2 } Positive & $0.105+\mathrm{j} 1.645[\mathrm{pu}]$ & \multirow{2}{*}{$100[\mathrm{MVA}]$} \\
\cline { 1 - 2 } Negative & $0.105+\mathrm{j} 1.645[\mathrm{pu}]$ & $154[\mathrm{kV}]$ \\
\hline Zero & $0.294+\mathrm{j} 3.372[\mathrm{pu}]$ & \\
\hline
\end{tabular}

\subsection{Scott Transformer}

The railway system is composed to two single-phases for up-line rail and down-line. If the railway system is supplied without any appropriate type of transformer, severe unbalance might be caused. To prevent the unbalance on the power system, the Scott transformer should be applied on railway substation. The Scott transformer is to balance 3-phase source circuit with transformation from 3-phase circuit to two single phase circuits by using two singlephase transformers. Winding configurations can be seen on Fig. 2.

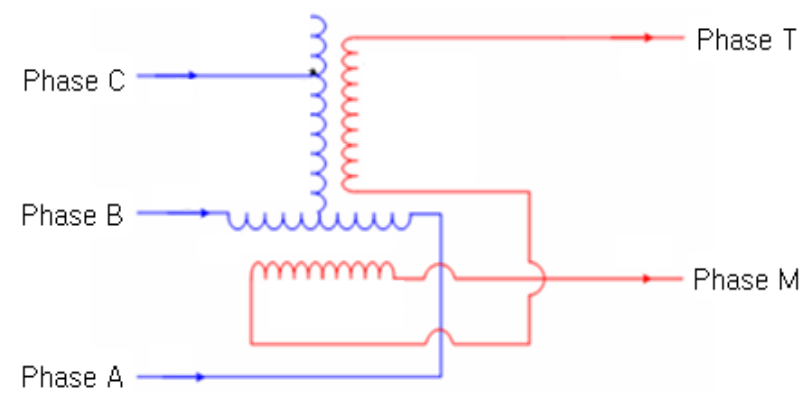

Fig. 2. Scott transformer windings.

Because the Scott transformers converts 3-phase circuit into two single phase circuits, the single phase MVA capacity of secondary winding is to be the half of the 3-phase capacity. Therefore, impedance $Z_{T R}$ of phase $M$ or $T$ are calculated by following Eq. 1 .

$$
Z_{T R}=\% Z_{T R} \frac{10 \cdot V^{2}}{P_{T R} / 2}[\Omega]
$$

Here, $\mathrm{Z}_{\mathrm{TR}}$ : Impedance of phase $\mathrm{M}$ or $\mathrm{T}$

$\% Z_{\mathrm{TR}}$ : Percent impedance of Scott transformer

$\mathrm{V}:$ Rated voltage $(55[\mathrm{kV}])$

$\mathrm{P}_{\mathrm{TR}}:$ 3-phase capacity of Scott transformer [kVA]

\subsection{Autotransformer}

Because distance between two railway substations is about $40 \sim 50[\mathrm{~km}]$, it is important to keep AC voltage rated value against voltage drop across line impedance. Also, since communication lines are installed in parallel with feeders and the current on feeder fluctuates sharply with electric vehicle drive mode, the inductive interference may cause communication error severely. Therefore, the Korean AC railway systems utilize autotransformers to mitigate voltage drop and inductive interference. Two terminals and neutral line of autotransformer are connected to feeder, contact wires and rails.

\subsection{Modeling on EMTDC}

In the model of the railway system, the source system and Scott transformer can be modeled as shown Fig. 3. The source model is composed Thevenin equivalent voltage source for the KEPCO system substation, transmission line between KEPCO system and railway substation, and Scott 
transformer. The Fig. 4 illustrates autotransformer model and its connection with railway catenary system.

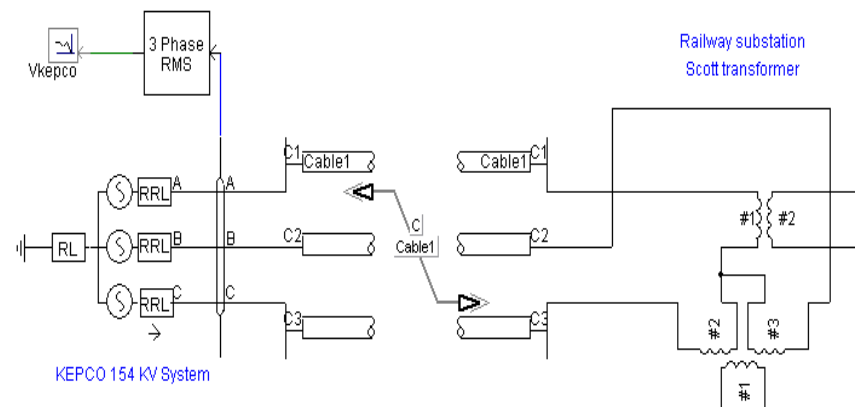

Fig. 3. KEPCO power system and Scott transformer.

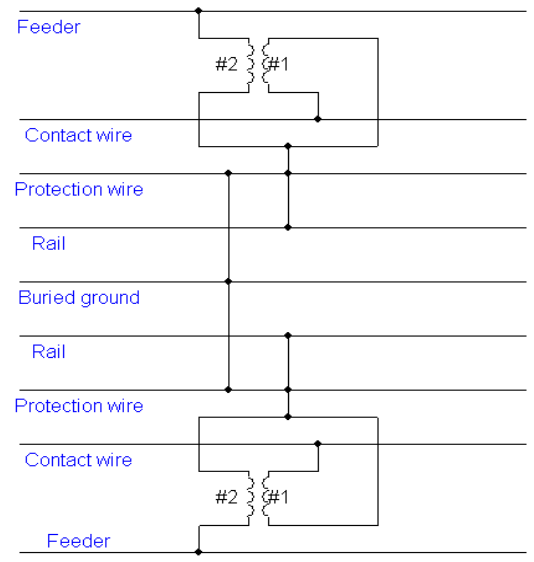

Fig. 4. Autotransformer and catenary system.

\section{Catenary Systems}

The catenary system which is located between two autotransformers is composed of 14 conductors. Fig. 5 illustrates catenary system which is composed of feeders, contact wires, protect wires, messenger wires, earth wires and

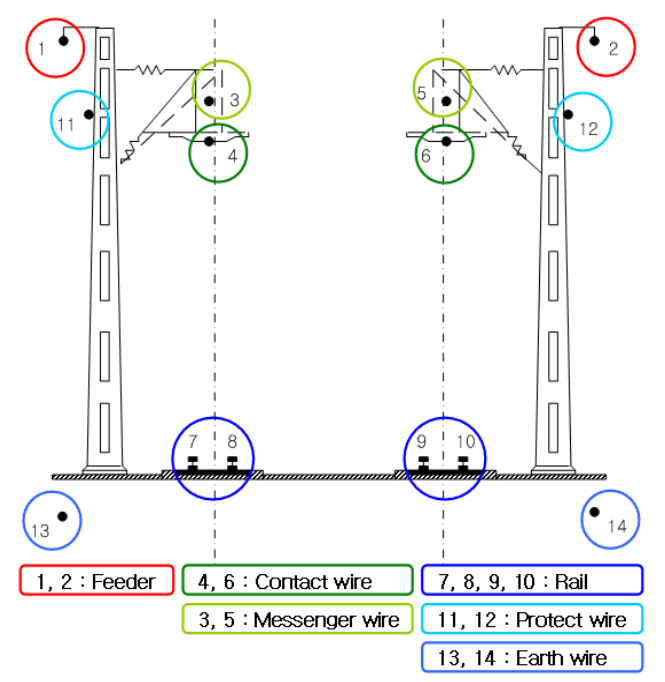

Fig. 5. Catenary system : actual conductor configuration. two rails for up-line and down-line. The existing researches had proposed that the catenary system could be expressed by 5 -conductors reduced equivalent model which represents two feeders, two contact wire conductors groups, and rail conductors group [3]. However, because this paper suggests a novel fault location technique by sensing boost wire current, the boost wire and the impedance bond should be separately expressed. The conductor grouping methodology is explained below.

\subsection{Self-impedance of Equivalent Conductor}

As shown on Fig. 6, assuming equivalence of two conductors which are bonded isoelectrically, the selfimpedance of the virtual conductor can be calculated by Eq. 2 .

$$
Z_{1}=\frac{Z_{a a} \cdot Z_{b b}-Z_{a b}^{2}}{Z_{a a}+Z_{b b}-2 Z_{a b}}
$$

Here, $Z_{\text {aa }}$ : Self-impedance of conductor A

$Z_{\mathrm{bb}}:$ Self-impedance of conductor B

$Z_{\mathrm{ab}}$ : Mutual impedance between conductor A and B

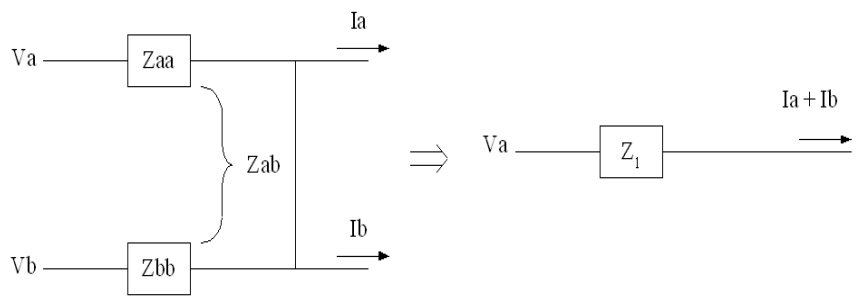

Fig. 6. Self-impedance of virtual conductor.

\subsection{Mutual Impedance Between Conductors}

To determine the mutual impedance between conductors are as important as self-impedance. It should be considered for two cases; conductor to equivalent conductor and equivalent conductor to equivalent conductor.

Fig. 7 illustrates the case to calculate mutual impedance

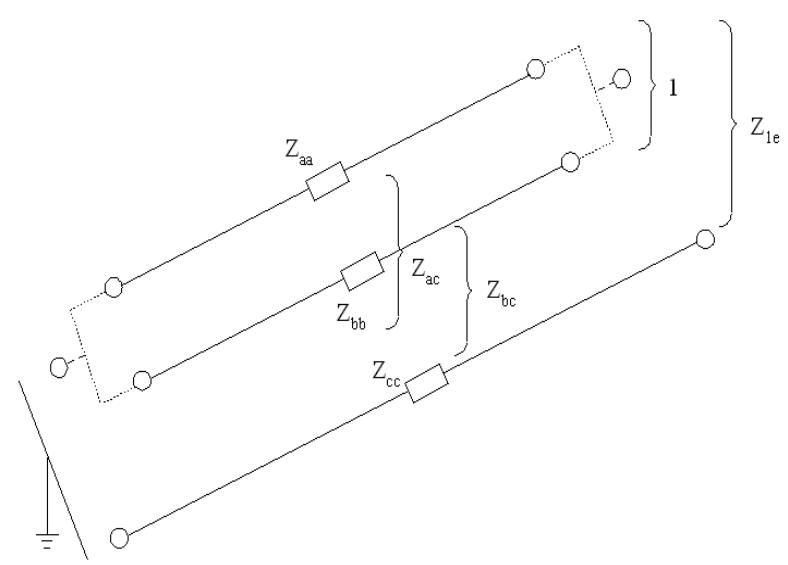

Fig. 7. Mutual impedance between conductor and equivalent conductor. 
between conductor and equivalent conductor. The mutual impedance, $Z_{1 c}$, can be calculated by Eq. 3 .

$$
Z_{1 c}=\frac{Z_{a c}\left(Z_{b b}-Z_{a b}\right)+Z_{b c}\left(Z_{a a}-Z_{a b}\right)}{Z_{a a}+Z_{b b}-2 Z_{a b}}
$$

Here, $Z_{\mathrm{aa}}$ : Self-impedance of conductor A

$\mathrm{Z}_{\mathrm{bb}}$ : Self-impedance of conductor B

$\mathrm{Z}_{\mathrm{cc}}$ : Self-impedance of conductor $\mathrm{C}$

$\mathrm{Z}_{\mathrm{ac}}$ : Mutual impedance between conductor $\mathrm{A}$ and $\mathrm{C}$

$\mathrm{Z}_{\mathrm{bc}}$ : Mutual impedance between conductor B and $\mathrm{C}$

Also, the mutual impedance, $\mathrm{Z}_{12}$, between two equivalent conductors, as shown in Fig. 8, can be calculated by Eq. 4 .

$$
Z_{12}=\frac{Z_{2 a}\left(Z_{b b}-Z_{a b}\right)+Z_{2 b}\left(Z_{a a}-Z_{a b}\right)}{Z_{a a}+Z_{b b}-2 Z_{a b}}
$$

Here, $Z_{\mathrm{aa}}$ : Self-impedance of conductor A

$\mathrm{Z}_{\mathrm{bb}}$ : Self-impedance of conductor B

$\mathrm{Z}_{\mathrm{cc}}$ : Self-impedance of conductor $\mathrm{C}$

$\mathrm{Z}_{\mathrm{dd}}:$ Self-impedance of conductor $\mathrm{D}$

$\mathrm{Z}_{2 \mathrm{a}}$ : Mutual impedance between conductor $\mathrm{A}$ and equivalent conductor 2

$\mathrm{Z}_{2 \mathrm{~b}}$ : Mutual impedance between conductor B and equivalent conductor 2

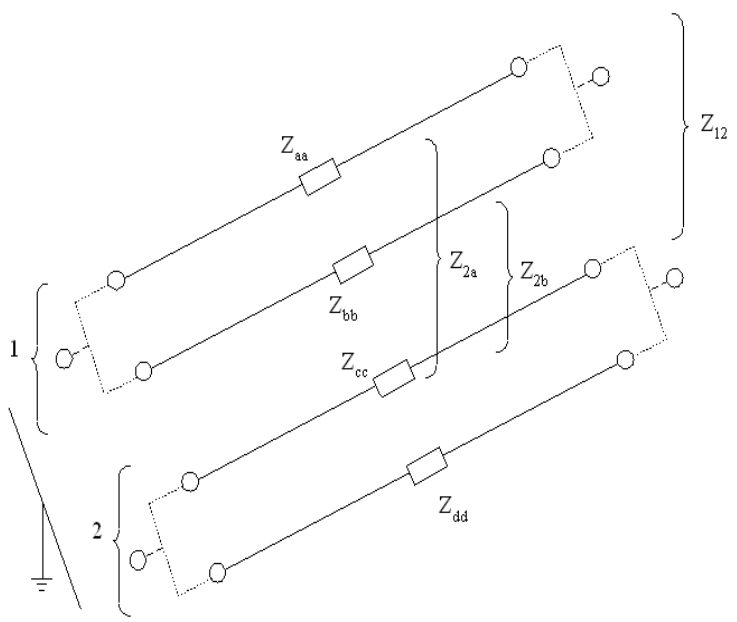

Fig. 8. Mutual impedance between equivalent conductors.

\subsection{Catenary System of Korean AC Railway System}

Using the formulas in section 3.1 and 3.2, the equivalent catenary conductor model has been constructed. Although positions of each conductor are different by the characteristics of the track, it is assumed that the track is on open track area in this paper. The positions of the catenary on open track area are illustrated in Fig. 9 and Table 2. Characteristics of each conductor are listed on Table 3 .

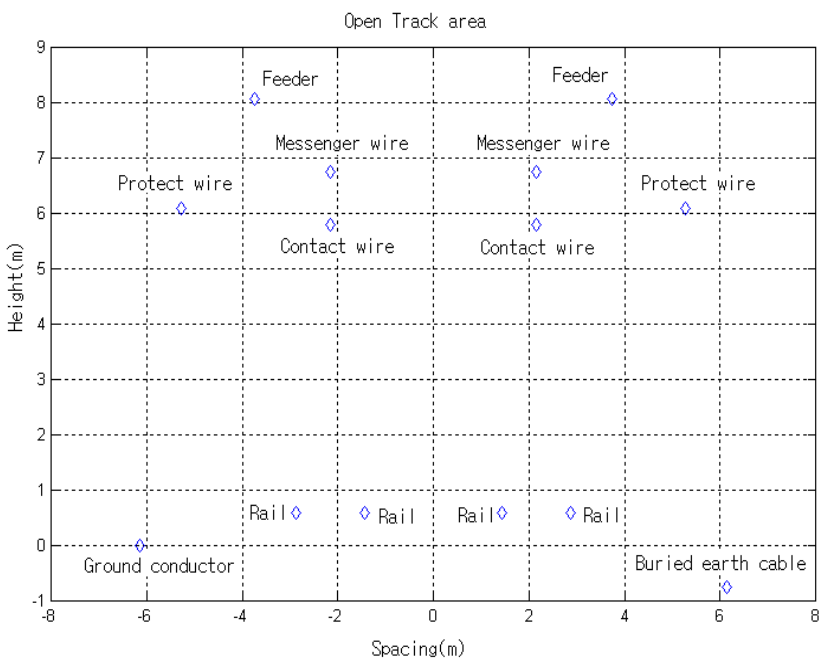

Fig. 9. Positions of conductors on open track area.

Table 2. Geometrical positions of the conductors on the open track area

\begin{tabular}{c|c|c}
\hline \multicolumn{3}{|c}{ Up-line } \\
\hline Conductors & $\mathrm{X}[\mathrm{m}]$ from center point & $\mathrm{Y}[\mathrm{m}]$ from center point \\
\hline Rail 1 & -2.87 & 0.60 \\
\hline Rail 2 & -1.43 & 0.60 \\
\hline Contact wire & -2.15 & 5.80 \\
\hline Messenger wire & -2.15 & 6.76 \\
\hline Feeder & -3.75 & 8.06 \\
\hline Protection wire & -5.28 & 6.10 \\
\hline Earth wire & -6.15 & -0.75 \\
\hline & Down-line & \\
\hline Conductors & $\mathrm{X}[\mathrm{m}]$ from center point & $\mathrm{Y}[\mathrm{m}]$ from center point \\
\hline Rail 1 & -2.87 & 0.60 \\
\hline Rail 2 & -1.43 & 0.60 \\
\hline Contact wire & -2.15 & 5.80 \\
\hline Messenger wire & -2.15 & 6.76 \\
\hline Feeder & -3.75 & 8.06 \\
\hline Protection wire & -5.28 & 6.10 \\
\hline Earth wire & -6.15 & -0.75 \\
\hline & &
\end{tabular}

Table 3. Characteristics of the conductors

\begin{tabular}{c|c|c|c|c}
\hline Conductor & Ohm $/ \mathrm{km}$ & Material & Size $\left(\mathrm{mm}^{2}\right)$ & Diameter $(\mathrm{cm})$ \\
\hline Feeder & 0.1173 & $\mathrm{Cu}$ & 150 & 1.35 \\
\hline Messenger wire & 0.4474 & $\mathrm{Al}$ & 65.49 & 1.05 \\
\hline Contact wire & 0.1173 & $\mathrm{Cu}$ & 150 & 1.36 \\
\hline Rail & 0.0126 & & 7639 & 7.7 \\
\hline Protection wire & 0.239 & $\mathrm{Cu}$ & 75.25 & 1.11 \\
\hline Earth wire & 0.484 & $\mathrm{Cu}$ & 37.16 & 0.78 \\
\hline
\end{tabular}

\subsection{Boost Wires and Impedance Bonds}

Impedance bond is an electrical connection between two rails and earth wire. It performs a role as a ground of the electric railway system. Also, it makes the two rail conduc- 


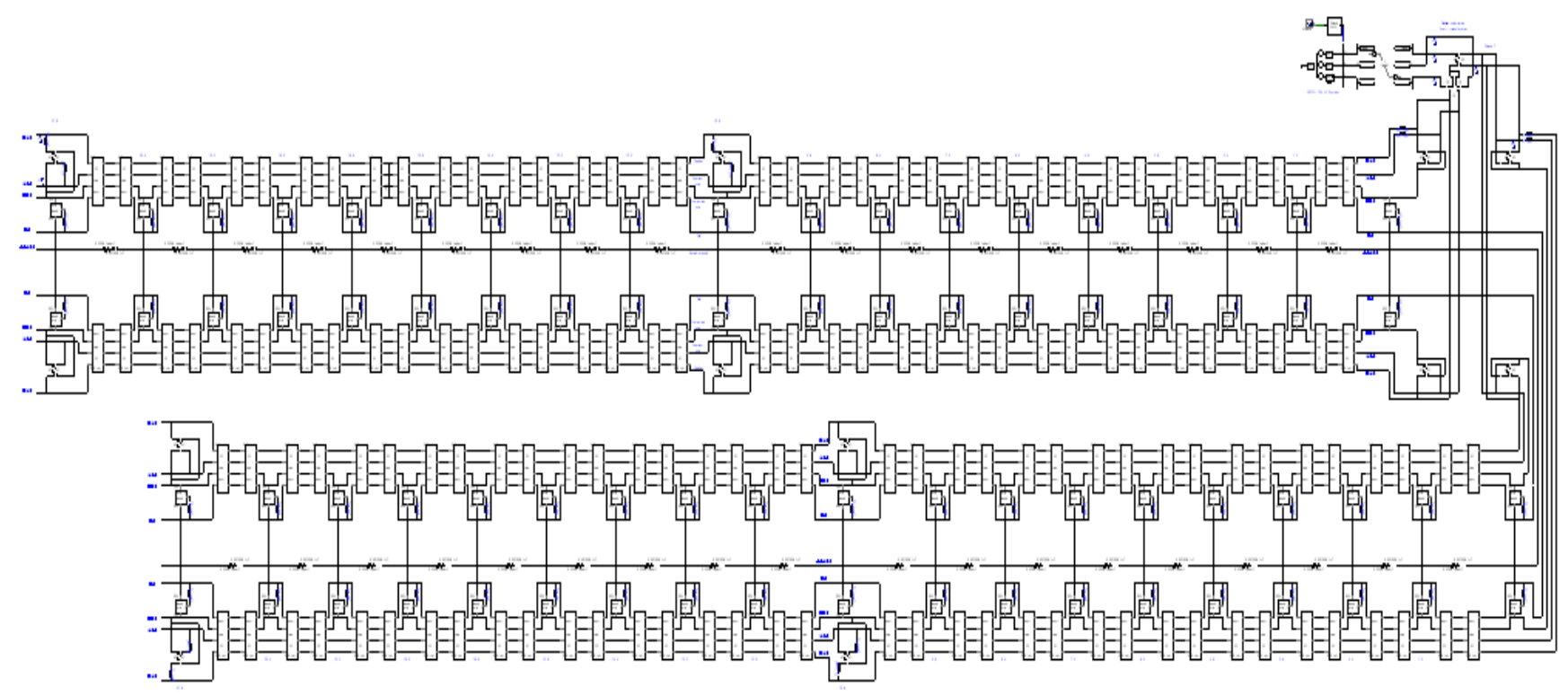

Fig. 10. Railway systems modeled on PSCAD/EMTDC.
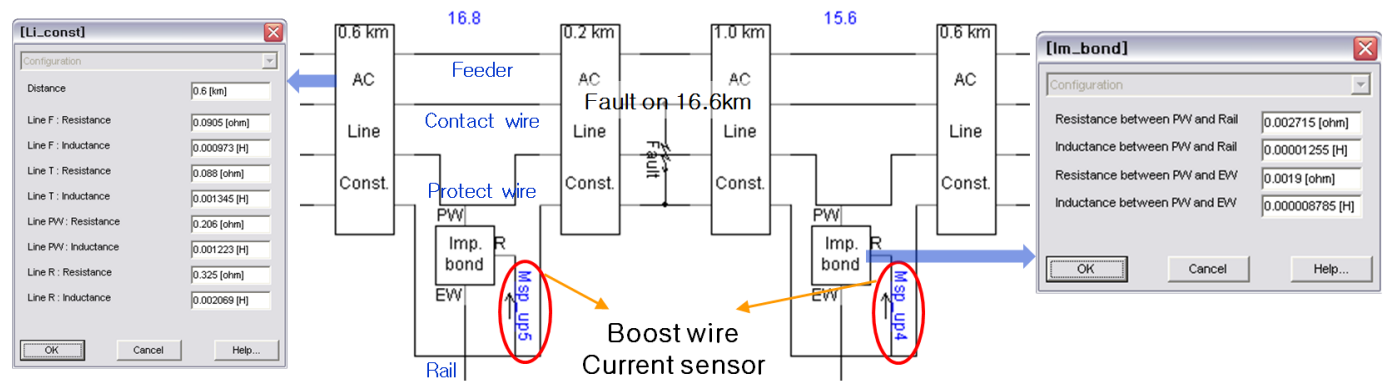

Fig. 11. Boost wires and current sensors.

tors and earth wire isoelectric. For another function, it is used to detect the location of the railway vehicle by using high frequency signal generating and receiving.

Boost wire is an electrical connection between the protection wire and the middle point of the impedance bond. Its function is to absorb the current flowing through the rails to avoid the inductive coupling interference with communication line. On Korean railway system, the impedance bond and boost wire are installed in every $1.2[\mathrm{~km}]$.

\section{EMTDC Railway Systems}

In this paper, EMTDC (Electro-Magnetic Transient Design and Control) is chosen to analyze the system and the railway system is constructed as seen on Fig. 10. This system is modeled for two sectioning post for $43.2[\mathrm{~km}]$. That is, it includes one railway substation at the center of it and two parallel posts between section post and substation.

The system can be divided for four parts and each part has eight boost wires. The current sensors on boost wires are installed as seen on Fig. 11. The railway system on Fig. 10 includes 64 current sensors on boost wires. As shown in Fig. 11, there are 'AC Line Constant' modules. This mod- ule includes catenary system which is reduced and reconstructed as mentioned on Section 3.

\section{Case Studies}

The novel fault location scheme finds faults by calculating the current ratio on two boost wire which has maximum current values. That is, the main point of this algorithm is to find two specific boost wires and maximum values and to calculate current ratio. The first operation is to find fault location roughly and the second operation is to determine accurate location in that section obtained by the fist operation. In this Section, the case studies perform various fault cases by fault types and several conditions.

\subsection{Fault Location for Contact Wire to Ground Fault}

The faults between contact wire and ground are the most frequent faults in the railway system, because contacts wires are physically contacted with the railway vehicle by pantograph. Actually, since the electric vehicle moves fast, contact wires are subjected to wear. In Section 5.1, the fault on $16.6[\mathrm{~km}]$ is assumed as seen on Fig. 12. 


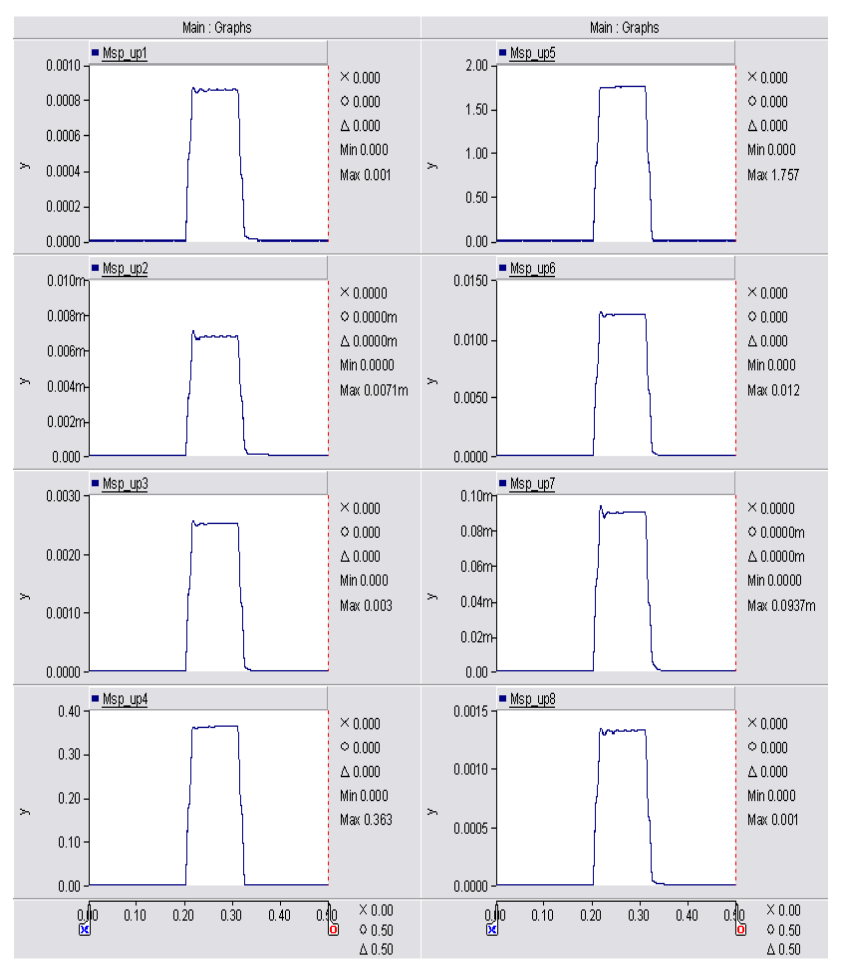

Fig. 12. Current on boost wires(kA).

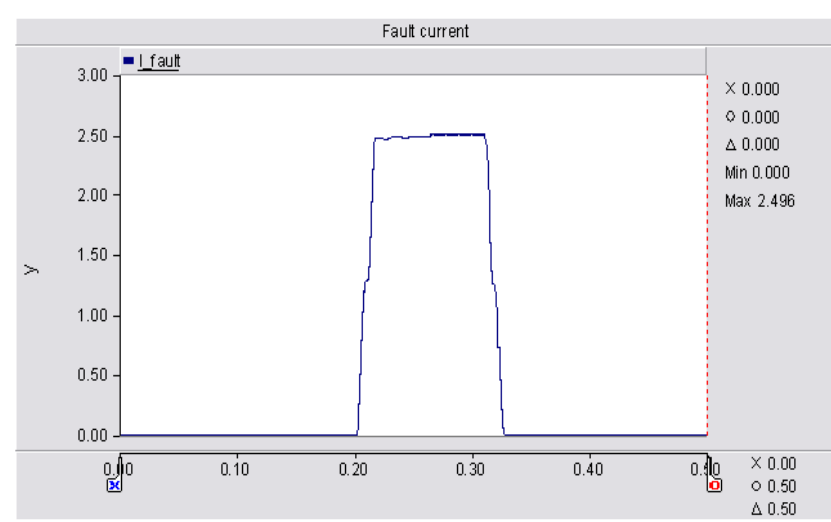

Fig. 13. Fault current.

Fig. 12 illustrates the current magnitude on each boost wire and Fig. 13 illustrates the magnitude of the fault current. On Fig. 12, the fourth and the fifth boost wires have maximum values. (Other 56 current sensors have much lower value) That is, we can find that the fault location is between $15.6[\mathrm{~km}]$ and $16.8[\mathrm{~km}]$.

The fourth sensor value is $0.363[\mathrm{kA}]$ and the fifth value is $1.757[\mathrm{kA}]$. By the current division rule, we can determine the accurate distance from the fourth boost wire as Eq. 5 . Finally, the accurate fault location can be determined as Eq. 6.

$$
\begin{gathered}
1.2 \times \frac{1.757}{1.757+0.363}=0.9945[\mathrm{~km}] \\
15.6+0.9945=16.5945[\mathrm{~km}]
\end{gathered}
$$

\subsection{Fault Location for Feeder to Ground Fault}

When the faults between feeder and ground are occurred, measured values on boost wires and the magnitude of the fault current are listed on Table 4. For the values on Table 4, the fault location can be calculated as $16.5946[\mathrm{~km}]$.

Table 4. Simulation results for feeder-to-ground fault on $16.6[\mathrm{~km}]$

\begin{tabular}{c|c|c|c}
\hline & Current(kA) & & Current(kA) \\
\hline BW \#1 & 0.000615 & BW \#2 & 0.0000135 \\
\hline BW \#3 & 0.003 & BW \#4 & 0.395 \\
\hline BW \#5 & 1.913 & BW \#6 & 0.013 \\
\hline BW \#7 & 0.00011 & BW \#8 & 0.001 \\
\hline \multicolumn{2}{|c|}{ Fault current } & \multicolumn{2}{|c}{$2.718[\mathrm{kA}]$} \\
\hline
\end{tabular}

\subsection{Fault Location for Various Fault Impedances}

Fault impedance on Section 5.1 and 5.2 was assumed to be 0.01 [Ohm]. On Section 5.3, fault location scheme for various fault impedances has been analyzed.

The fault is still on $16.6[\mathrm{~km}]$ and fault type is contact wire to ground fault. Regarding that the base case is on part 5.1, case 3-1 has 0.1 [Ohm] fault impedance and case 3-2 has $0.5[\mathrm{Ohm}]$. In a practical manner, although it is announced that the fault impedance just determines the magnitude of fault current, the various cases are simulated to verify whether it has an effect on the novel fault location scheme. The results are listed on Table 5.

Table 5. Simulation results for various values of fault im-

\begin{tabular}{|c|c|c|c|c|c|}
\hline & Cases & $\begin{array}{c}\text { Current } \\
(\mathrm{kA})\end{array}$ & & Cases & $\begin{array}{c}\text { Current } \\
(\mathrm{kA})\end{array}$ \\
\hline \multirow{3}{*}{$\begin{array}{c}\text { BW } \\
\# 1\end{array}$} & Basecase & 0.000871 & \multirow{3}{*}{$\begin{array}{l}\text { BW } \\
\# 2\end{array}$} & Basecase & 0.000007 \\
\hline & Case 3-1 & 0.000870 & & Case 3-1 & 0.000007 \\
\hline & Case 3-2 & 0.000863 & & Case 3-2 & 0.000007 \\
\hline \multirow{3}{*}{$\begin{array}{c}\text { BW } \\
\# 3\end{array}$} & Basecase & 0.003 & \multirow{3}{*}{$\begin{array}{c}\text { BW } \\
\# 4\end{array}$} & Basecase & 0.363 \\
\hline & Case 3-1 & 0.003 & & Case 3-1 & 0.363 \\
\hline & Case 3-2 & 0.003 & & Case 3-2 & 0.361 \\
\hline \multirow{3}{*}{$\begin{array}{c}\text { BW } \\
\# 5\end{array}$} & Basecase & 1.757 & \multirow{3}{*}{$\begin{array}{c}\text { BW } \\
\# 6\end{array}$} & Basecase & 0.012 \\
\hline & Case 3-1 & 1.756 & & Case 3-1 & 0.012 \\
\hline & Case 3-2 & 1.747 & & Case 3-2 & 0.012 \\
\hline \multirow{3}{*}{$\begin{array}{c}\text { BW } \\
\# 7\end{array}$} & Basecase & 0.000094 & \multirow{3}{*}{$\begin{array}{c}\text { BW } \\
\# 8\end{array}$} & Basecase & 0.001 \\
\hline & Case 3-1 & 0.000093 & & Case 3-1 & 0.001 \\
\hline & Case 3-2 & 0.000092 & & Case 3-2 & 0.001 \\
\hline \multirow{3}{*}{\multicolumn{2}{|c|}{ Fault current }} & \multicolumn{2}{|c|}{ Basecase } & \multicolumn{2}{|c|}{$2.496[\mathrm{kA}]$} \\
\hline & & \multicolumn{2}{|c|}{ Case 1} & \multicolumn{2}{|c|}{$2.495[\mathrm{kA}]$} \\
\hline & & \multicolumn{2}{|c|}{ Case 2} & \multicolumn{2}{|c|}{$2.483[\mathrm{kA}]$} \\
\hline
\end{tabular}
pedance

From Table 5, fault locations of each case can be calculated $16.5945,16.5935$, and $16.5945[\mathrm{~km}]$, respectively. It can be concluded that the fault impedance does not influence fault location of the novel one. 


\subsection{Fault Location with Electric Vehicle}

It is needed to verify whether the electric vehicle gives an effect on fault locating. Based on the same fault on Section 5.1, two cases are suggested. Case 4-1 is with electric vehicle that is far from the fault and case 4-2 is with electric vehicle that is close to the fault. Table 6 summarizes the simulation results.

From Table 6, fault locations of each case can be calculated $16.5945,16.5943$, and 16.5943 [km], respectively. It can be concluded that the existence does not influence the novel fault location scheme.

Table 6. Simulation results for various location of electric vehicle

\begin{tabular}{|c|c|c|c|c|c|}
\hline & Cases & $\begin{array}{l}\text { Current } \\
\text { (kA) }\end{array}$ & & Cases & $\begin{array}{c}\text { Current } \\
(\mathrm{kA})\end{array}$ \\
\hline \multirow{3}{*}{$\begin{array}{c}\text { BW } \\
\# 1\end{array}$} & Basecase & 0.000871 & \multirow{3}{*}{$\begin{array}{c}\text { BW } \\
\# 2\end{array}$} & Basecase & 0.000007 \\
\hline & Case 1 & 0.002 & & Case 1 & 0.272 \\
\hline & Case 2 & 0.000878 & & Case 2 & 0.000008 \\
\hline \multirow{3}{*}{$\begin{array}{c}\text { BW } \\
\# 3\end{array}$} & Basecase & 0.003 & \multirow{3}{*}{$\begin{array}{c}\text { BW } \\
\# 4\end{array}$} & Basecase & 0.363 \\
\hline & Case 1 & 0.272 & & Case 1 & 0.368 \\
\hline & Case 2 & 0.003 & & Case 2 & 0.372 \\
\hline \multirow{3}{*}{$\begin{array}{l}\text { BW } \\
\# 5\end{array}$} & Basecase & 1.757 & \multirow{3}{*}{$\begin{array}{c}\text { BW } \\
\# 6\end{array}$} & Basecase & 0.012 \\
\hline & Case 1 & 1.779 & & Case 1 & 0.012 \\
\hline & Case 2 & 1.798 & & Case 2 & 0.013 \\
\hline \multirow{3}{*}{$\begin{array}{l}\text { BW } \\
\# 7\end{array}$} & Basecase & 0.000094 & \multirow{3}{*}{$\begin{array}{c}\text { BW } \\
\# 8\end{array}$} & Basecase & 0.001 \\
\hline & Case 1 & 0.000094 & & Case 1 & 0.001 \\
\hline & Case 2 & 0.000095 & & Case 2 & 0.001 \\
\hline \multirow{3}{*}{\multicolumn{2}{|c|}{ Fault current }} & \multicolumn{2}{|c|}{ Basecase } & \multicolumn{2}{|c|}{$2.496[\mathrm{kA}]$} \\
\hline & & \multicolumn{2}{|c|}{ Case 1} & \multicolumn{2}{|c|}{$2.531[\mathrm{kA}]$} \\
\hline & & \multicolumn{2}{|c|}{ Case 2} & \multicolumn{2}{|c|}{$2.558[\mathrm{kA}]$} \\
\hline
\end{tabular}

\section{Conclusions}

This paper suggests the novel fault location scheme to overcome location error of existing scheme. The problem of existing one is that it indicates 200 [m] fault location error due to $10[\mathrm{~km}]$ distance between current sensors. Therefore, the novel one suggests installing current sensors on boost wires which is located per $1.2[\mathrm{~km}]$.

To model the railway system including boost wires and impedance bonds, the existing 5-conductors catenary system model should be modified to 9-conductors model. Actual 14 conductors are reduced to 9 conductor groups by the methodology that is explained Section 3. With this 9conductors model, the railway system is constructed on PSCAD/EMTDC

Through Section 5, the novel fault location scheme has verified that the fault location for any fault type can be calculated accurately. Also, it has been verified that the scheme has little error without concerning the fault impedance or the location of railway vehicle.

By applying the novel fault location scheme, it is expected that maintenance with stable railway operations and higher efficiency can be realized.

\section{References}

[1] Hanmin Lee, Gildong Kim, Sehchan Oh, Gilsoo Jang, Sae-hyuk Kwon, "Fault analysis of Korean AC electric railway system," Electric Power System Research, Vol. 76, Issue 5, pp. 317-326, Mar. 2006

[2] J. Kim, Power System and Protection Scheme on Electric Railway System, Vol. 1, Kidari, Korea, 2004, p. 262.

[3] Hanmin Lee, Kwanghae Oh, Changmu Lee, Sanghoon Chang, Gilsoo Jang, Saehyuk Kwon, "A Reduced Equivalent 5-Conductor Modeling of the Catenary Systme," The Transaction of the KIEE, Vol. 52A, No. 12, pp. 684-690, Dec. 2003

[4] Hanmin Lee, Kwanghae Oh, Changmu Lee, Hyunjune Park, Gilsoo Jang, Saehyuk Kwon, "A Reduced Equivalent Line Constant of the Catenary System," The Transaction of the KIEE, Vol. 53-A, No. 8, pp. 421-431, Aug. 2004

[5] B. Yang, Advanced Electric Railway Engineering, vol. 1, Sungandang, Korea, 2003, p. 230, p.319

[6] P. Wilson, PSCAD User's Guide, HVDC Research Centre, Canada, 2003

[7] Z. Xu, M. Liu, G. Yang, and N. Li, "Application of interval analysis and evidence and evidence theory to fault location," IET Electric Power Applications, Vol. 3, Issue1, pp. 77-84, Jan. 2009

[8] Chih-Ju Chou, Ying-Tung Hsiao, Jhane-Li Wang, Yaw-Tzong Hwang, "Distribution of earth leakage currents in railway systems with drain autotransformer," IEEE Trans. Power Delivery, Vol. 16, Issue 2, pp. 271-275, Apr. 2001

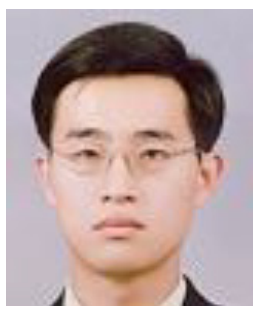

Changmu Lee received his M.S. degree in Electronic Communication Engineering from Hanyang University in 1994 and finished the coursework towards his doctorate in Electrical Engineering from Korea University. $\mathrm{He}$ has worked for Korea Railroad Research Institute as a Senior Researcher in Advanced EMU Research Division.

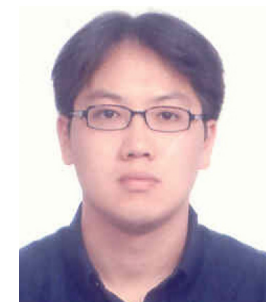

Hansang Lee was born in Korea in 1980. He received B.S. and M.S. degree in electric engineering from Korea University, Korea. He is currently pursuing Ph.D. degree at Korea University graduate school. His research interests include railway system, power quality, renewable generation, and energy storage system. 


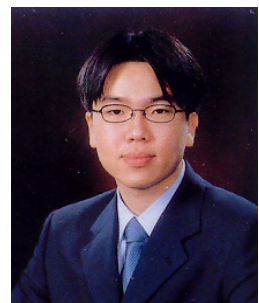

Dong-Hee Yoon was born in Korea in 1981. He received B.S. degree in electric engineering from Korea University, Korea. He is currently pursuing Ph.D. degree at Korea University graduate school. His research interests include wind power system, dispersed generation and HVDC system.

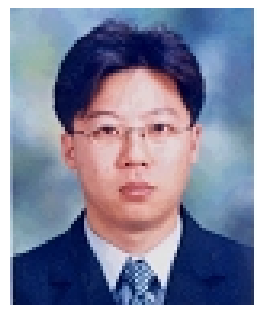

Hanmin Lee received his M.S. and Ph.D. degree in Electrical Engineering from Korea University, Seoul, Korea in February 2000 and February 2005, respectively. He has worked for Korea Railroad Research Institute as a Senior Researcher in Advanced EMU Research Division.

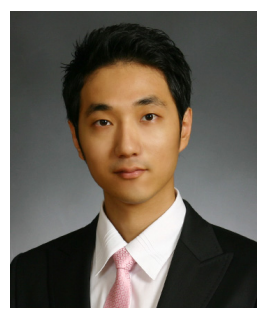

Jiyoung Song received the B.S. degrees from Hanyang University, Seoul, Korea in 2008. He is currently pursuing his M.S degree at Korea University. His research interests include microgrid and energy storage system.

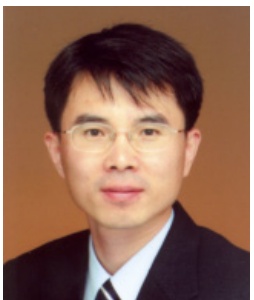

Gilsoo Jang received his B.S. and M.S. degree from Korea University, Korea. $\mathrm{He}$ received his $\mathrm{Ph}$. D. degree from Iowa State University in 1997. He worked in Electrical and Computer Engineering Department at Iowa State University as a Visiting Scientist for one year, and at Korea Electric Power Research Institute as a researcher for 2 years. He is presently an Assistant Professor of School of Electrical Engineering at Korea University. His research interests include power quality and power system control.

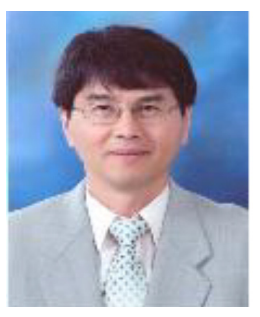

Byungmoon Han received his B. S. in Electrical Engineering from Seoul National University, Korea, in 1976, and his M. S. and Ph.D. from Arizona State University in 1988 and 1992, respectively. He was with the Westinghouse Electric Corporation as a Senior Research Engineer in the Science and Technology Center. Currently he is a Professor in the Department of Electrical Engineering at Myongji University, Korea. His research interests are in power electronics applications for FACTS, custom power, and distributed generation 